\title{
Menyalakan Api Literasi Dengan Grow Me
}

\section{Wahyu Kris Aries Wirawardana}

SMPK Pamerdi

wahjoekris@gmail.com

\section{Article History}

accepted 01/12/2020

\begin{abstract}
SMPK Pamerdi Kabupaten Malang does not have library facilities. However, SMPK Pamerdi has great efforts to build literacy. The literacy movement developed at SMPK Pamerdi is GROW ME which stands for Goal (goal), Reality (reality), Option (choice), Will (plan), Monitoring (monitoring), Evaluation (evaluation). Students read books at home on their own schedule. Every Monday there is a discussion about telling books that are read in groups with the accompanying teacher. The research revealed that grade IX students read an average of 12 books in 32 months, class VIII 9 books in 15 months, and class VII 4 books in 3 months.
\end{abstract}

Keywords: literacy, GROW ME

\begin{abstract}
Abstrak
SMPK Pamerdi Kabupaten Malang tidak memiliki fasilitas ruang perpustakaan. Namun, SMPK Pamerdi punya ikhtiar besar membangun literasi. Gerakan literasi yang dikembangkan di SMPK Pamerdi adalah GROW ME yang merupakan kependekan dari Goal (tujuan), Reality (realitas), Option (pilihan), Will (rencana), Monitoring (pemantauan), Evaluation (evaluasi). Siswa membaca buku di rumah dengan jadwal yang ditentukan sendiri. Setiap Senin ada diskusi menceritakan buku yang dibaca dalam kelompok bersama guru pendamping. Peneltian mengungkapkan bahwa siswa kelas IX rata-rata membaca 12 buku dalam waktu 32 bulan, kelas VIII 9 buku dalam waktu 15 bulan, dan kelas VII 4 buku dalam waktu 3 bulan.
\end{abstract}

Kata kunci: literasi, GROW ME

Social, Humanities, and Education Studies (SHEs): Conference Series https://jurnal.uns.ac.id/shes 


\section{PENDAHULUAN}

Sebagai bangsa dengan budaya lisan yang kental, Indonesia memiliki tantangan tersendiri dalam membangun budaya literasi. Masyarakat Indonesia cenderung berkomunikasi secara lisan. Unsur- unsur kebudayaan diteruskan dari generasi ke generasi berikutnya secara lisan. Ketika teknologi informasi tiba-tiba datang dengan kecepatan yang tak terbayangkan sebelumnya, maka upaya membangun budaya literasi yang berbasis baca - tulis pun semakin berat.

Enam belas tahun silam, Indonesia bersama 188 negara lainnya yang tergabung dalam PBB berkomitmen untuk melakukan perubahan total. Deklarasi komitmen tersebut termaktub dalam 8 visi Millenium Development Goals (MDG"s) yang salah satunya adalah mewujudkan pendidikan dasar untuk semua. Visi mewujudkan pendidikan dasar ini bisa menjadi pemicu sekaligus pemacu pembangunan manusia mengingat begitu besarnya sumber daya manusia di Indonesia.

Pada tahun 2020 hingga 2030, Indonesia diprediksi akan menikmati puncak bonus demografi, yaitu ledakan penduduk dengan usia produktif lebih dari $70 \%$. Bonus ledakan penduduk ini bisa berubah menjadi ancaman jika Indonesia gagal mempersiapkan generasi. Kegagalan mempersiapan generasi akan berdampak pada melemahnya daya saing bangsa. Untuk itu, Indonesia harus menetapkan langkah untuk menyiapkan generasi dengan kualitas literasi mumpuni. Sekolah merupakan salah satu ladang terbaik untuk menyemai budaya literasi tersebut.

Berkaitan dengan kondisi literasi Indonesia, ada beberapa data yang layak diperhatikan. Di antaranya adalah sebagai berikut:

1. Hasil penelitian Programme for International Student Assessment (PISA) 2019 memaparkan bahwa skor membaca Indonesia ada di peringkat 72 dari 77 negara, lalu skor matematika ada di peringkat 72 dari 78 negara, dan skor sains ada di peringkat 70 dari 78 negara.

2. Survey Programme for International Assessment of Adult Competencies (PIAAC) tahun 2016 mengungkapkan bahwa Indonesia berada urutan ke- 34 dari 34 negara. Survey terhadap penduduk usia 16 - 55 tahun ini menguji tingkat literasi, numerasi dan kemampuan memecahkan masalah. Nilai rata-rata capaian Indonesia masih dibawah angka 1 dari nilai teringgi yaitu 5 .

3. Data Badan Pusat Statistik menunjukkan bahwa anak Indonesia menghabiskan waktu 300 menit per hari untuk menonton televisi. Angka ini cukup memprihatinkan bila dibandingkan dengan anak-anak Australia yang 150 menit, anak - anak Amerika 100 menit, dan anak- anak Kanada hanya 60 menit. Di regional ASEAN yang rata-ratanya 120 sampai 180 menit, angka ini praktis menjadi yang tertinggi.

Literasi bukan sekadar tentang kemampuan baca tulis. Literasi terkait erat dengan cara pandang, cara berpikir, cara bersikap, dan cara menyelesaikan masalah. Dalam http://bibliotech.us/pdfs/InfoLit.pdf, Ferguson memaparkan bahwa literasi mencakup 5 kemampuan, yaitu:

1. Basic literacy (literasi dasar). Literasi dasar terdiri atas kemampuan untuk membaca-menulis, mendengarkan-berbicara, mencacah- menghitung, dan mengamatimenggambarkan.

2. Library literacy (literasi perpustakaan). Literasi perpustakaan berkaitan dengan penggunaan katalog, membedakan fiksi dengan non-fiksi, serta pemahaman sistem Dewey. Literasi ini merupakan kemampuan dasar untuk mencari, menemukan, mengolah, dan memanfaatkan informasi.

3. Media literacy (literasi media). Literasi media berkaitan dengan kemampuan untuk membedakan opini dengan fakta yang tersebar melalui beragam media seperti 
media cetak, media elektronik dan media digital. Literasi ini merupakan dasar untuk bersikap kritis.

4. Technology literacy (literasi teknologi). Literasi teknologi bukan sekadar kemampuan menyalakan dan mematikan perangkat teknologi. Bukan pula sekadar memahami perangkat keras dan menggunakan perangkat lunak. Literasi teknologi lebih berkait erat dengan bagaimana menggunakan teknologi secara bijak dan positif.

Visual literacy (literasi visual). Literasi visual merupakan irisan litersi media dengan literasi teknologi. Literasi ini berkaitan dengan kemampuan untuk mengritisi media visual ataupun audio visual yang dihasilkan dari manipulasi perangkat teknologi. Literasi ini menjadi sangat penting mengingat begitu melimpahnya media yang memungkinkan terjadinya perbedaan persepsi dan opini.

Karl Schmidt mengatakan kebudayaan suatu bangsa dimulai dengan penciptaan literatur dan penggunaan tulisan. Tak mengherankan jika untuk mengetahui perkembangan awal suatu kota atau daerah maka yang dijadikan titik tolak adalah prasasti atau peningggalan tulisan masa silamnya. Hal ini menegaskan bahwa kegiatan literasi merupakan langkah awal membangun budaya bangsa.

Jika literasi Indonesia bisa berkembang dari kebiasaaan menjadi gaya hidup kemudian terus menjadi budaya maka Indonesia akan menjadi bangsa yang berbudaya maju. Apalagi dengan bonus demografi yang semakin dekat, kemajuan budaya literasi akan melipatgandakan dampak positifnya terhadap daya saing bangsa di tengah percaturan dunia. Dan, lahan paling tepat untuk menyemai budaya literasi adalah sekolah.

Pada hakikatnya, sekolah bukanlah bangunan dimana peserta didik datang pagi pulang sore tanpa mengalami proses pendidikan. Sekolah adalah entitas sosial yang mendidik masyarakat agar hidup dalam peradaban ilmiah, saling menghargai, dan mencapai kesejahteraan atau kebahagiaan (Kasali, 2014). Peradaban ilmiah merupakan peradaban yang salah satu pilarnya adalah sikap kritis. Hal ini bisa dikenalkan kepada peserta didik sedini mungkin. Salah satunya adalah melalui pengembangan kegiatan literasi dengan melatih peserta didik untuk mengunyah dan mencerna buku, bukan sekadar membaca dan menghafal. Dengan mengunyah buku, di dalam diri peserta didik akan terbangun keingintahuan yang merupakan titik awal menjadi manusia pembelajar (Harefa, 2000).

Lebih lanjut, Kasali (2014) menegaskan bahwa tujuan pendidikan adalah memperbaiki cara berpikir peserta didik, sekaligus membebaskannya dari berbagai belenggu yang mengikatnya. Cara berpikir peserta didik akan berubah dan berkembang tak terbatas jika mendapat latihan literasi secara kontinyu. Dengan demikian, sekolah harus berani out of the box, keluar dari kotak budaya anti-literasi menuju sekolah berbudaya literasi.

Anjuran menteri pendidikan nasional melalui Permendikbud No 23 tahun 2015 agar peserta didik membaca buku non pelajaran 15 menit di awal pembelajaran layak diapresiasi. Efektifkah 15 menit per hari? Menurut penulis kurang efektif. Menjadikan kegiatan membaca sebagai kewajiban justru bisa menjadi bumerang. Apalagi waktunya hanya 15 menit. Banyak waktu akan terbuang sia-sia jika membaca ini hanya menjadi rutinitas dan formalitas.

Kegiatan membaca perlu dilengkapi dengan tekad bulat dan semangat kuat untuk membangun budaya literasi. Dengan budaya literasi, sekolah akan terhindar dari pendidikan feodal yang memiskinkan jiwa merdeka, memiskinkan kehidupan, dan memiskinkan rasa seni budaya, serta memiskinkan pikiran (Darmaningtyas, 2015). Untuk itu, sekolah perlu mengambil langkah nyata sesuai kondisi dan konteks daerah. 
Dibutuhkan pula kesatuan visi seluruh warga sekolah terutama pendidik untuk menjadi teladan membangun budaya literasi.

\section{GROW ME: Bergerak Mewujudkan Tujuan \\ HASIL DAN PEMBAHASAN}

SMP Kristen Pamerdi merupakan sekolah swasta di pinggiran Kabupaten Malang. Tepatnya berada di Jalan Raya kebonagung 05 Desa Kebonagung Kecamatan Pakisaji. Dari segi sarana prasarana, SMP Kristen Pamerdi bisa dikatakan sangat terbatas. Jumlah ruang yang tersedia hanya 1 ruang guru yang di dalamnya ada ruang TU dan kepala sekolah, 3 ruang kelas, 1 laboratorium komputer yang digunakan bersama dengan unit TK dan SD, 1 ruang praktik keterampilan, dan 1 ruang yang digunakan untuk dapur sekaligus UKS. Halaman sekolah untuk upacara pun harus berbagi dengan unit TK dan SD. Jadi, tidak ada lapangan olahraga dan ruang khusus bernama perpustakaan. Keterbatasan ruang inilah yang menyebabkan kegiatan membaca anak-anak terabaikan.

Sejak 2012, SMP Kristen Pamerdi punya tekad kuat untuk menyemai budaya literasi di sekolah. Nihilnya ruang perpustakaan tak boleh jadi penghalang. Anggaran buku ditingkatkan tiap tahun. Beberapa donatur memberikan sumbangan buku dalam jumlah cukup banyak. Alhasil, SMP Kristen Pamerdi memiliki ribuan buku aneka jenis bacaan non pelajaran. Buku-buku disimpan dalam 3 lemari dengan memanfaatkan sudut kelas dan lorong sekolah. Sayangnya, selama 3 tahun, ribuan buku tersebut tak sanggup menggugah semangat membaca. Kegiatan literasi di sekolah seakan terkubur mati suri. Rendahnya semangat berliterasi para guru menjadi salah satu penyebabnya. Anak anak yang sedang butuh "pupuk penyubur" literasi pun kembali layu sebelum berkembang. Tahun 2014, seluruh guru kembali duduk bersama. Evaluasi terhadap layunya literasi sekolah menjadi tema diskusi. Sekolah mencoba mengatasi tantangan ini dengan metode GROW ME yang merupakansingkatan dari Goal, Reality, Options, Will, Monitoring dan Evaluation. GROW ME pertama kali dikenalkan oleh Ng Pak Tee (2004)

Dengan adaptasi sesuai kebutuhan, sekolah menerapkan GROW ME dengan konsep sebagai berikut:

GOAL (Tujuan)

SMP Kristen Pamerdi menetapkan tujuan yaitu peserta didik memiliki semangat literasi yang tinggi dengan jumlah bacaan minimal 5 buku per tahun.

REALITY (Kenyataan)

Tujuan-tujuan yang sudah ditetapkan di atas bukan sekadar pajangan. Bukan pula kalimat kosong tanpa makna. Tujuan adalah pemacu sukaligus pemicu bagi sekolah untuk bergerak nyata mewujudkannya. Usaha ini tentu tak mudah karena ada kenyataan yang harus dihadapi, yaitu tidak adanya ruang perpustakaan. Namun, sekolah mampu melihat kenyataan kedua: sekolah punya tujuan untuk membangun budaya literasi. Kenyataan inilah yang memberikan energi jauh lebih besar daripada kenyataan pertama.

OPTION (Pilihan)

Melihat dua kenyataan di atas, ada beberapa pilihan yang harus dipilih salah satu. Setiap pilihan mengandung risiko. Pilihan pertama: sekolah membatalkan tujuan. Ini adalah pilihan paling mudah karena sekolah dan guru tidak perlu repot menjadi teladan dalam membangun budaya literasi. Namun, di balik pilihan paling mudah tersebut ada risiko yang sangat berat, yaitu kemunduran peserta didik karena tidak memiliki budaya literasi. Pilihan kedua: Sekolah menunda pewujudan tujuan sampai sekolah memiliki ruang perpustakaan sendiri. Pilihan ini sedikit lebih lebih baik 
dibandingkan pilihan pertama karena masih ada semangat untuk membangun budaya literasi. Namun, selain tidak ada kepastian waktu, penundaan merupakan kerugian karena waktu dan kesempatan tak akan datang dua kali. Padahal, membangun budaya litersi merupakan sesuatu yang penting dan mendesak. Pilihan ketiga: sekolah langsung bergerak mewujudkan tujuan. Pilihan ini adalah pilihan paling berat karena ada tantangan yang harus dihadapi. Beberapa tantangan tersebut antara lain adalah: Di manakah peserta didik akan berliterasi jika sekolah tak punya perpustakaan?

WILL (Rencana)

Pertanyaan - pertanyaan di atas membuat sekolah berpikir ulang. Namun, akhirnya sekolah mantap memilih pilihan ketiga, yaitu langsung bergerak mewujudkan tujuan. Beberapa strategi pun mulai disusun agar semangat membangun budaya literasi tidak rontok di tengah jalan. Untuk menjawab pertanyaan-pertanyaan di atas, sekolah menyusun perencanaan pembangunan budaya literasi dengan konsep sebagai berikut: 1. Kegiatan penyalaan api literasi SMP Kristen Pamerdi diberi nama GROW ME dengan kegiatan utama berupa Kuman Buku. Kuman Buku merupakan singkatan dari Kunyah Buku dan Prasmanan Buku.

2. Kunyah buku adalah membaca buku yang dilakukan peserta didik di rumah masing-masing. Peserta didik merdeka menentukan waktu dan durasi membacanya. Sekolah tidak memberikan target kepada peserta didik untuk menyelesaikan kunyah buku.

3. Setiap hari Senin jam 07.00 - 09.00 ada „Prasmanan" Buku. Peserta didik berkumpul dalam kelompok yang terdiri atas 8 - 10 orang dengan 1 guru pendamping. Setiap peserta didik dalam kelompok prasmanan ini menceritakan sebagian buku yang dibacanya selama seminggu. Peserta didik yang lain dipersilahkan bertanya jawab, mengonfirmasi, dan/atau menambahkan.

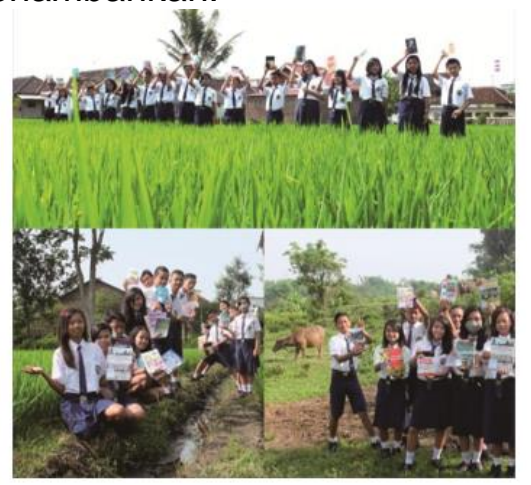

Gambar 1. Jalan pagi di areal persawahan belakang sekolah untuk meningkatkan kebugaran peserta didik sebelum Grow Me

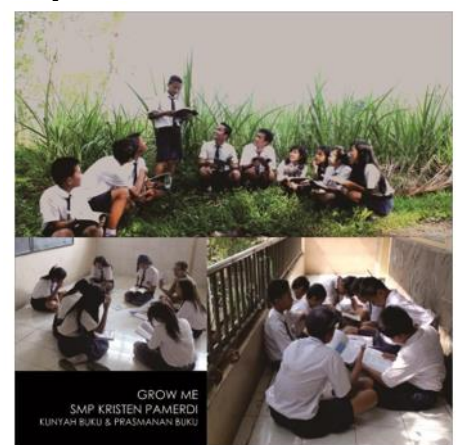

Gambar 2. Kebun tebu, sudut kelas, dan lorong sekolah adalah tempat favorit prasmanan buku 


\section{MONITORING (Pengawasan)}

Untuk memastikan bahwa Grow Me berjalan sesuai rencana, peserta didik menyiapkan buku khusus untuk Grow Me. Buku ini digunakan untuk menulis resume bagian buku yang dibacanya. Setelah prasmanan, buku ini diperiksa dan ditandatangani oleh guru pendamping. Tak lupa guru pendamping menulis sekalimat motivasi untuk membakar semangat peserta didik dalam berliterasi.

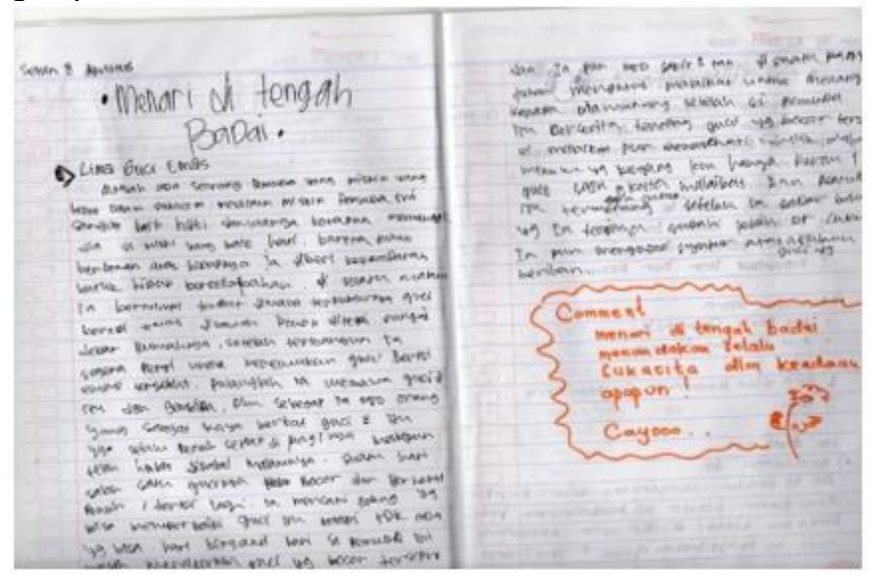

\section{Gambar 3. Salah satu resume yang ditulis peserta didik}

\section{EVALUATION (Evaluasi)}

Untuk evaluasi, peserta didik menerima lembar evaluasi untuk menuliskan beberapa hal terkait dengan Grow Me. Di antaranya adalah berapa jumlah buku yang dibacanya selama mengikuti Grow Me, buku apakah yang paling berkesan, dampak apakah yang dirasakan setelah Grow Me, dan masukan untuk perbaikan Grow Me.

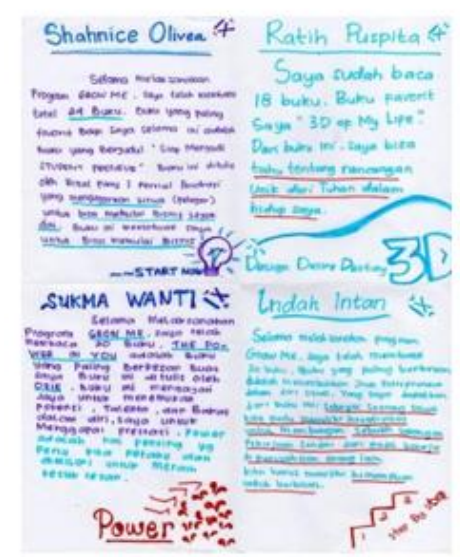

Gambar 4 Komentar Siswa Terhadap Kegiatan GROW ME

Jumlah buku yang dibaca peserta didik tersaji pada Tabel 1, Tabel 2, dan Tabel 3.

1. Tabel 1 Jumlah buku yang dibaca siswa kelas IX Jan 2017 - Okt 2019

\begin{tabular}{ccc}
\hline Jumlah buku yang dibaca & Frekuensi (jumlah siswa) & Persentase \\
\hline $1-5$ & 2 & $8 \%$ \\
$6-10$ & 5 & $20 \%$ \\
$11-15$ & 3 & $12 \%$ \\
\hline
\end{tabular}




\begin{tabular}{ccc}
\hline $16-20$ & 12 & $48 \%$ \\
$21-25$ & 3 & $12 \%$ \\
Jumlah & 25 & $100 \%$ \\
Rata - rata 12 buku per 32 bulan atau 5 buku per tahun & \\
\hline
\end{tabular}

Tabel 2. Jumlah buku yang dibaca siswa kelas VIII Jul 2018 - Okt 2019

\begin{tabular}{ccc}
\hline Jumlah buku yang dibaca & Frekuensi (jumlah siswa) & Persentase \\
\hline $6-10$ & 16 & $67 \%$ \\
$11-15$ & 7 & $29 \%$ \\
$16-20$ & 1 & $4 \%$ \\
Jumlah & 24 & $100 \%$ \\
Rata - rata 9 buku per 15 bulan atau 7 buku per tahun & \\
\hline
\end{tabular}

Tabel 3. Jumlah buku yang dibaca siswa kelas VII Jul 2019 - Okt 2019

\begin{tabular}{ccc}
\hline Jumlah buku yang dibaca & Frekuensi (jumlah siswa) & Persentase \\
\hline $1-5$ & 16 & $80 \%$ \\
$6-10$ & 3 & $15 \%$ \\
$11-15$ & 1 & $5 \%$ \\
Jumlah & 20 & $100 \%$
\end{tabular}

Rata - rata 4 buku per 3 bulan atau 16 buku per tahun

\section{SIMPULAN}

Berdasarkan paparan pembangunan budaya literasi melalui Grow Me kunyah buku dan prasmanan buku, dapat ditarik kesimpulan sebagai berikut:

1. Dengan GROW ME kunyah buku dan prasmanan buku, semangat literasi peserta didik meningkat. Hal ini tampak pada jumlah buku yang melebihi target semula.

2. Untuk kelas IX, setiap siswa rata-rata membaca 12 buku dalam waktu 32 bulan

3. Untuk kelas VIII, setiap siswa rata-rata membaca 9 buku dalam waktu 15 bulan

4. Untuk kelas VII, setiap siswa rata-rata membaca 4 buku dalam waktu 3 bulan.

Upaya membangun budaya literasi ini harus terus dikembangkan agar bisa memberikan dampak bagi kemajuan bangsa. Untuk itu, penulis memiliki harapan sebagai berikut:

1. Kegiatan GROW ME Kuman Buku (kunyah buku dan prasmanan buku) perlu dikembangkan dengan kegiatan menulis resensi. Sehingga kemampuan literasi peserta didik akan semakin kuat dan komplit.

2. Kerjasama dengan orang tua perlu ditingkatkan. Salah satu bentuknya adalah dengan melibatkan orang tua untuk turut bergabung kunyah buku di rumah ataupun prasmanan buku di sekolah dalam waktu tertentu. 
3. Para pendidik harus berani mengembangkan kapasitas diri dan kompetensi profesional, sosial, kepribadian, serta pedagoginya di bidang literasi. Salah satunya adalah dengan menciptakan inovasi pembelajaran berbasis literasi.

4. Dinas pendidikan terkait harus lebih giat lagi menjalin koordinasi dan sinergi dengan seluruh institusi pendidikan dalam membangun budaya literasi. Salah satunya adalah melalui workshop, semiloka, lomba ataupun festival berbasis literasi.

Pemerintah daerah perlu mengambil langkah konkrit untuk mendukung terbangunnya budaya literasi di wilayah masing-masing. Penerbitan peraturan daerah tentang penguatan budaya literasi bisa menjadi alternatif. Di samping itu, pemerintah juga harus terus mengeksplore potensi ekonomi kreatif daerah di bidang literas

\section{DAFTAR PUSTAKA}

Darmaningtyas. 2015. Pendidikan Yang Memiskinkan. Malang: Intrans Publishing Ferguson, Brian. Information Literacy. http://bibliotech.us/pdfs/InfoLit.pdf, Diakses Sabtu, 12 November 2019 pukul 17.03 .

Harefa,Andreas. 2000. Menjadi Manusia Pembelajar. Jakarta: PT Kompas Media Nusantara

Kasali, Rhenald. 2014. Let's Change! Jakarta: Penerbit Buku Kompas. 2015. Self Driving: Menjadi Driver atau Passenger?. Jakarta: Penerbit Mizan

Seely, Levi. 2015. History of Education. Diterjemahkan oleh Sutrisno. Yogyakarta: Penerbit Indoliterasi.

Subagio, Kusumo. 5 November 2016. Rendahnya Pendidikan Kita. Kompas, halaman 3.

Tee, Ng Pak. 2004. GROW ME Coaching for School. Singapura: Prentice Hall Pearson Education South Asia 